Departamento de Historia Universidad de Santiago de Chile

Revista de Historia Social

y de las Mentalidades

Volumen 24, $\mathrm{N}^{\circ}$ 2, 2020: 177-212

Issn Online: 0719-4749

\title{
LOS CUADERNOS DE OSVALDO ROMO. DUDAS Y DESAFÍOS PARA EL ARCHIVO DOCUMENTAL DEL PARQUE POR LA PAZ VILLA GRIMALDI EN TORNO A LA FIGURA DEL REPRESOR*
}

\author{
THE NOTEBOOKS OF OSVALDO ROMO. DOUBTS AND CHALLENGES FOR \\ THE DOCUMENTARY ARCHIVE OF THE PARQUE POR LA PAZ VILLA GRIMALDI \\ AROUND THE FIGURE OF THE PERPETRATORS
}

LIC. NATHALIA RUBIO URREJOLA**

Corporación Parque por la Paz Villa Grimaldi

Santiago, Chile

Email: nathalia.rubio@villagrimaldi.cl Id-ORCID: 0000-0003-3100-4082

MG. OMAR SAGREDO MAZUELA Corporación Parque por la Paz Villa Grimaldi / Universidad Academia de Humanismo Cristiano

Santiago, Chile

Email: omar.sagredo@villagrimaldi.cl Id-ORCID: 0000-0003-4481-4260

\begin{abstract}
RESUMEN
El presente artículo describe y analiza el proceso de incorporación de los cuadernos del fallecido agente civil de la Dirección de Inteligencia Nacional (DINA)

Osvaldo Romo Mena al Archivo Documental del sitio de memoria Parque por la Paz Villa Grimaldi. A diferencia de las discusiones generales que atraviesan a todos los archivos de derechos humanos

ABSTRACT

This article describes and analyzes the process of incorporating Osvaldo Romo Mena's notebooks (deceased civil agent of the Directorate of National Intelligence) into the Archive of the site of memory Parque por la Paz Villa Grimaldi. Unlike the general perspective of human rights archives in Chile, regarding disclosure,
\end{abstract}

* $\quad$ Recibido: 20 de diciembre 2019; Aprobado: 4 de abril 2020.

** Ensayo. Este artículo es resultado de un estudio de interés personal de los autores y no representa, necesariamente, el pensamiento del Directorio de la Corporación Parque por la Paz Villa Grimaldi, ni de los trabajadores que la conforman. Los autores agradecen la revisión de Daniel Rebolledo y Maeva Schwend. 
en Chile acerca de su revelación, apertura y uso, estos documentos presentan un desafío adicional: su veracidad. Se propone estudiar este asunto desde un dilema doble: como un problema de la archivística del campo de la memoria y los derechos humanos y como una situación controversial asociada a la "duda" que representa el abordaje de los represores para la investigación en un sitio de memoria.

Palabras clave: Archivos de Derechos Humanos; Parque por la Paz Villa Grimaldi; duda; represores accessibility and use, these documents present an additional challenge: their veracity. It is proposed to study this issue from a double dilemma: as a problem in the field of human rights archives and as a controversial situation associated with the "doubt" that the study about perpetrators represents for research in a site of memory.

Keywords: Human Rights Archives; Parque por la Paz Villa Grimaldi; Doubt; Perpetrators

Cómo citar: Rubio, Nathalia y Omar Sagredo. (2020). "Los cuadernos de Osvaldo Romo. Dudas y desafíos para el archivo documental del Parque por la Paz Villa Grimaldi en torno a la figura del represor". Revista Historia Social y de las Mentalidades, 24(2), 177-212. DOI: 10.35588/rhsm.v24i2.4284

\section{INTRODUCCIÓN}

Los archivos de derechos humanos en sociedades post-autoritarismo son un elemento clave para el desarrollo de la justicia transicional, principalmente, en materia de verdad, justicia y reparación para las víctimas (Da Silva Catelda 388). En tanto elementos asociados al enfrentamiento de pasados violentos y dictatoriales, estos archivos son asuntos relevantes en el presente, pues no solo representan evidencia respecto de las violaciones a los derechos humanos, sino que, además, permiten la construcción y preservación de la memoria colectiva, simbolizan un encuadre orientador, en términos éticos, de la praxis archivística y contribuyen a las disputas acerca de los distintos sentidos que se asignan sobre del pasado (Giraldo 125), posibilitando, incluso, una discusión acerca del olvido y el perdón (Agüero 277-279).

En América Latina, estos documentos responden también a luchas políticas entre, por una parte, verdad e impunidad y, por otro lado, propiedad pública o privada (Zerán et al. 12-13; Ortiz 86), siendo una expresión material del avance democratizador de las políticas de justicia (Jelin 184-185). A medida que los procesos de transición a la democracia avanzan, a los expedientes históricos formados durante los períodos autoritarios se suman archivos creados por la sociedad civil en post-dictadura. ${ }^{1}$ En Chile, estos documentos corresponden,

1 Destacan los trabajos realizados en la formación de archivos orales de sobrevivientes del terrorismo de Estado de las dictaduras de Brasil y Argentina del Programa de Historia Oral del 
mayoritariamente, a acervos elaborados por "emprendedores de memoria" organizados como resultado tanto de los procesos de recuperación y apertura de sitios de memoria, como de la continuación de las labores de organismos de derechos humanos. Actualmente, todos estos documentos son parte de un extenso debate político relativo a su apertura y uso público (Iduarte, "La experiencia" 94), condicionados por la presión social del movimiento de derechos humanos (Elgueta 57-60) y la contingencia política acerca de su encubrimiento y/o destrucción (Jara y López 2018).

No obstante, a pesar de la generalidad de estos desafíos comunes para los archivos de derechos humanos, existe una notoria pregunta no abordada acerca de los documentos personales generados por exagentes de los organismos represivos. ¿Pueden estos ser una fuente de información válida? En relación con lo anterior, ¿dónde deben estar depositados? No se trata de los denominados "archivos de la represión" (Groppo 38), es decir, documentación relativa a los organismos represivos -la cual, por cierto, es muy escasa-, sino de manuscritos elaborados por quienes fueron parte de las estructuras responsables de las violaciones a los derechos humanos. El acercamiento a documentos de esta naturaleza implicaría un desafío bidimensional. Por una parte, el abordaje de la figura controversial de los represores como un objeto de estudio de la historia reciente (Salvi, "El universo" 23), en particular, la presencia de su voz en el espacio público (Feld y Salvi 6). Por otro lado, la apertura de nuevas interrogantes sobre el sentido y el estatus de "verdad" de los archivos de derechos humanos, en el marco del denominado "giro del archivo" (Guasch 2), en especial, en lo relativo al entendimiento de estos documentos como objetos de investigación en sí mismos y no solo como fuentes (Bernasconi, "Del Archivo" 71).

Evidenciando lo anterior, en este artículo se aborda la situación de los cuadernos escritos por el fallecido agente civil de la Dirección de Inteligencia Nacional (DINA), Osvaldo Romo Mena, en específico, su incorporación al Archivo Documental del sitio de memoria Parque por la Paz Villa Grimaldi (PPVG) en 2012. A diferencia de las discusiones generales que atraviesan a todos los archivos de derechos humanos en Chile (revelación -para el caso de los archivos en poder de las Fuerzas Armadas- y apertura y uso -en lo referido al acervo del Informe de la Comisión Nacional sobre Prisión Política

Centro de Pesquisa e Documentação de História Contemporânea do Brasil y de Memoria Abierta en Argentina, respectivamente. Para profundizar en su composición y desarrollo, se recomienda revisar las ponencias de Lucia Quillet y Alejandra Oberti en Acceso público a la memoria. El rol de los archivos testimoniales en la democratización de las sociedades postdictatoriales de Raúl Rodríguez et al. 
y Tortura-), estos documentos presentan un desafío adicional: su veracidad. En consideración de esta condicionante, se propone estudiar la incorporación de los manuscritos de Romo al PPVG desde un dilema doble. Por una parte, desde una perspectiva particular, como un problema de la archivística del campo de la memoria y los derechos humanos en un sitio como el PPVG. Por otro lado, desde una óptica general, como una situación controversial que representa un límite para las políticas de la memoria en tanto conlleva una importante cuota de "duda", no solo acerca de los hechos descritos, sino que además en la decisión de considerarlos. ${ }^{2}$

El escrito se estructura en cuatro secciones. Primero, una revisión conceptual acerca de los archivos de derechos humanos, su relación con la figura del represor y las limitantes planteadas por dudas clave, centrando la atención en el caso chileno y sus particularidades. Segundo, la descripción del Archivo Documental del PPVG. Tercero, el análisis de la incorporación de los cuadernos de Romo a este acervo, distinguiendo las principales problemáticas asociadas, desde el punto de vista de la "duda", y los medios prácticos implementados. Para realizar el análisis referente a la "incertidumbre" en estos documentos, se revisaron cinco de los cuadernos de Osvaldo Romo, de los cuales se extrajeron algunas frases literales donde este hace hincapié en la supuesta veracidad de su propio relato, con la finalidad de reconocer patrones en su discurso y tensionar su narrativa como posible fuente histórica. Finalmente, se presentan algunas conclusiones preliminares sobre cómo la experiencia del Archivo Documental del PPVG con los manuscritos de Romo representa un caso relevante para el estudio, no solo de los acervos de derechos humanos y situaciones controversiales, sino que, para el campo de investigación sobre los archivos de derechos humanos, los represores y las políticas de la memoria.

\section{LOS ARCHIVOS DE DERECHOS HUMANOS. BREVE SÍNTESIS.}

Desde el inicio de las transiciones a la democracia, luego de cruentos regímenes autoritarios o contextos de violencias, la búsqueda de la verdad sobre los hechos ocurridos se ha posicionado como una de las principales demandas relativas a la justicia transicional, en el marco del denominado "derecho a saber" (Bernales Rojas 265-268). Esta interpretación del pasado se

2 Se utilizará la definición de Joignant (2017) acerca de la "duda" como elemento hostil para el desarrollo de las políticas de la memoria. En el siguiente apartado, se profundiza en este punto. 
ha efectuado, principalmente, a través de la creación de comisiones de verdad (Millán 3), las cuales, obtienen información clave a partir de los archivos generados por organismos de defensa de los derechos humanos que operaron durante el periodo de violencia y/o terrorismo de Estado. Los antecedentes contenidos en estos documentos, así como los archivos en sí, una vez que se convierten en insumos para las comisiones de verdad, constituyen tanto pruebas judiciales para el avance de los procesos de penalización de los represores, como elementos de reparación simbólica para víctimas y familiares que ven cómo sus denuncias obtienen el valor de "verdad oficial" (Jelin 184-185). En este sentido, la obtención de reconocimiento público de los archivos de derechos humanos aporta, no solo cuotas de identidad política al movimiento de sobrevivientes y familiares, sino que, además, dota a estos documentos de una característica única de "reveladores" de hechos que fueron ocultados o negados durante los gobiernos dictatoriales (Da Silva Catela 396).

Por cierto, el posicionamiento de estos acervos en el presente postautoritarismo es un asunto generador de controversias. Jelin ha señalado, desde la experiencia latinoamericana, que tanto la figuración pública de los archivos de derechos humanos, como su utilización como fuente principal para los informes de verdad oficiales, ha implicado procesos de memorialización compuestos de luchas sociales y políticas respecto de su contenido, propiedad, acceso y respeto por la privacidad (190). Estos complejos asuntos tienden a ser analizados en un marco político que abarca a la oficialidad gubernamental y la sociedad civil, diferenciando a los acervos entre "archivos de memoria y derechos humanos" (Bernasconi et al., Guía 11), también llamados "archivos del dolor y la resistencia" o "archivos de la resistencia de la sociedad frente al terrorismo de Estado" (Groppo 44), y "archivos de la represión" (Da Silva Catela 395; Groppo, 37). Los primeros se refieren a la documentación producida o reunida por organismos de defensa de los derechos humanos, agrupaciones de víctimas de la violencia estatal y comisiones de verdad creadas por los gobiernos post-dictatoriales. En Chile, estos acervos corresponden, en primer lugar, al Informe de la Comisión Nacional de Verdad y Reconciliación de 1991 y los Informes de la Comisión Nacional sobre Prisión Política y Tortura de 2004 y su segunda versión de 2010. En segundo término, a aquellos elaborados por organismos de derechos humanos de la sociedad civil en dictadura y elaborados en democracia. Los primeros corresponden a los acervos de las Agrupaciones de Familiares de Detenidos Desaparecidos y Ejecutados Políticos, la Vicaría de la Solidaridad del Arzobispado de Santiago, la Fundación de Ayuda Social de las Iglesias Cristianas (FASIC), la Comisión Chilena de Derechos Humanos, la Corporación de Promoción y Defensa de los Derechos del Pueblo (CODEPU) y 
la Fundación para la Protección de la Infancia Dañada por Estados de Emergencia (PIDEE) (Herbst y Huenequeo; Iduarte, "La experiencia"; Bernasconi et al., Guía de archivos). Los segundos, elaborados en la postdictadura, corresponden, principalmente, a iniciativas que buscan no solo visibilizar las violaciones a los derechos humanos, sino también generar instancias de reflexión acerca de la vida política del Chile dictatorial, con enfoque museográfico y/o pedagógico: los Archivos Oral y Documental del Parque por la Paz Villa Grimaldi, del Museo de la Memoria y los Derechos Humanos y de Londres 38, y los Archivos Orales de la Fundación PIDEE y de la Casa de la Memoria de Coquimbo, y el Archivo Oral de la Maestranza Barón de Valparaíso.

Los archivos de derechos humanos representan también una instancia de contención y denuncia respecto de las políticas de olvido implementadas por el Estado, considerando que en Chile la dictadura cívico-militar utilizó distintos medios para garantizar la impunidad de sus crímenes: la Ley de Amnistía de 1978, la remoción de cuerpos de detenidos desaparecidos inhumados de manera ilegal, y la destrucción, ocultamiento, o apropiación de lugares de detención y tortura. Es comprensible así, que la relevancia fundamental de los acervos de derechos humanos en Chile haya sido reconocida en 2003 por la UNESCO, a través de la incorporación de varias de las colecciones documentales creadas en dictadura al Programa Memorias del Mundo.

Los archivos de la represión, por otro lado, se refieren a los expedientes generados por los gobiernos autoritarios, los órganos represores, o por sus redes nacionales e internacionales (Groppo 38). Por lo general, a esta categoría pertenecen no solo documentos oficiales de los organismos represivos acerca de sus acciones criminales, sino que también, declaraciones de víctimas obtenidas en sesiones de tortura y documentación relativa a juicios ilegítimos contra opositores. En el presente, su principal funcionalidad ha sido la de servir como prueba judicial para la asignación de responsabilidades a los exagentes (Da Silva Catela 398). En el caso chileno, estos archivos, que corresponden, principalmente, a los documentos relativos a los Consejos de Guerra contra prisioneros políticos y a aquellos generados por los organismos represores, la Dirección de Inteligencia Nacional (DINA) y su sucesora, la Central Nacional de Informaciones (CNI), han sido permanentemente negados por parte de las Fuerzas Armadas, aun cuando en el presente han existido referencias concretas sobre su existencia. ${ }^{3}$ En este sentido, tres hechos dan

3 Además de las evidencias nacionales, también se ha recuperado información acerca del accionar de los organismos represores chilenos en documentación internacional. En 2010, el gobierno estadounidense donó al Museo de la Memoria y los Derechos Humanos una serie de documentos 
cuenta de esta situación. Primero, en 2005, en el marco de la investigación sobre los crímenes cometidos en la ex Colonia Dignidad, el juez Jorge Zepeda incautó treinta y nueve mil fichas sobre violaciones a los derechos humanos que permanecieron en el enclave alemán. Segundo, en el mismo año, durante la realización de labores de mejoramiento de infraestructura, fueron encontrados documentos de la CNI con fecha de 1980 en el edificio del actual Museo de la Solidaridad Salvador Allende (Bernasconi et al., Guía 11). Por último, durante 2017, en el marco de la investigación por la muerte del expresidente Eduardo Frei Montalva, se reveló que el Ejército destruyó, de manera irregular, información microfilmada de la CNI. Esta acción habría ocurrido en el año 2000, durante el desarrollo de la denominada Mesa de Diálogo (instancia organizada por el gobierno de Eduardo Frei Ruiz-Tagle con el objetivo principal de obtener antecedentes por parte de los militares respecto del destino de los desaparecidos). La destrucción de esta información, ocurrida mientras Pinochet permanecía detenido en Londres, es materia de investigación todavía, buscando determinar responsabilidades. ${ }^{4}$

Ahora bien, toda esta diversa documentación ha sido objeto de profundos y transversales debates políticos durante parte importante de la post-dictadura chilena. La principal discusión se ha generado por el decreto oficial sobre la imposibilidad de acceder, por un período de 50 años, a los testimonios que fueron utilizados para la elaboración del Informe de la Comisión Nacional de Prisión Política y Tortura. Esta disposición ha sido considerada contraria al derecho a saber y conocer todas las dimensiones del terrorismo de Estado, siendo entendida como una batalla de la memoria aún en desarrollo (Bernasconi et al., "Las comisiones" 46). Actualmente, la campaña "No más archivos secretos" representa uno de los mayores esfuerzos de la sociedad civil por destrabar el conocimiento público de todos los testimonios y antecedentes, tanto de la Comisión Nacional de Prisión Política y Tortura, como de todos los archivos del Estado en dictadura (Iduarte, "La experiencia" 94). Otras controversias relevantes son la disposición legal que

de la CIA relativos a la intervención norteamericana en Chile durante la presidencia de Salvador Allende y acciones criminales de la dictadura que fueron de conocimiento de Estados Unidos. El Museo de la Memoria y los Derechos Humanos es también depositario de documentos sobre personas deportadas de Chile en los primeros meses luego del golpe de Estado de 1973 y que fueron donados por el Archivo de la ex Dirección de Inteligencia de la Policía de la Provincia de Buenos Aires (DIPBA). En 2015, el gobierno estadounidense realizó una nueva donación de expedientes desclasificados, los cuales, se encuentran en el Ministerio de Relaciones Exteriores (Bernasconi et al., Guía 11).

$4 \quad$ El desarrollo de esta noticia ha sido responsabilidad del área de investigaciones de Radio Biobío. Se puede revisar evolución de esta información en: Jara y López, 2018. 
exime a las Fuerzas Armadas de la obligación de depositar su documentación en el Archivo Nacional de Chile, así como también, respecto de la eventual entrega de los archivos de derechos humanos originados en dictadura al acervo oficial del Estado. ${ }^{5}$ Esta última situación se ha solucionado, en parte, puesto que la mayoría de los archivos incorporados al Programa Memorias del Mundo han decidido donar sus documentos al Museo de la Memoria y los Derechos Humanos. Sin embargo, la mayoría de los archivos creados por la sociedad civil después de 1990 continúan en propiedad de entidades privadas, las cuales, si bien se orientan a la promoción de los derechos humanos y la memoria histórica, están sujetas al devenir de las políticas públicas y fondos internacionales para conservar adecuadamente los documentos. Por último, una crítica transversal a los acervos de derechos humanos en Chile ha sido planteada por Elizabeth Lira, quien, bajo la consigna "los silencios de los archivos", ha señalado que esta documentación escasamente ha abordado las denuncias de abusos sexuales ocurridos durante la dictadura, se ha concentrado limitadamente en ciudades diferentes a Santiago, y no cuentan con certeza suficiente para afirmar que todas las víctimas han sido documentadas (Lira 194).

Un avance importante en esta materia ha ocurrido en Chile en los últimos tres años, a través de la declaración como Monumentos Históricos que el Consejo de Monumentos Nacionales ha realizado sobre los archivos de Colonia Dignidad en 2016, de la Vicaría de la Solidaridad en 2017, y de la Brigada Investigadora de Delitos contra los Derechos Humanos de la Policía de Investigaciones de Chile en 2018. Estos reconocimientos son parte de lo que Da Silva Catela ha denominado "los archivos como lugares de historia y memoria", en tanto, soportes documentales que son "instrumentos de conocimiento" y enseñanza, así como elementos que evocan directamente el pasado (Da Silva Catela 392). Otro progreso importante ha sido desarrollado por el Programa de Investigación Interdisciplinar en Memoria y Derechos Humanos de la Universidad Alberto Hurtado, a través del proyecto iniciado en 2015 "Tecnologías políticas de la memoria: Genealogía de los dispositivos de registro y denuncia por las violaciones a los derechos humanos cometidas durante la dictadura militar". ${ }^{6}$ Esta iniciativa, que propone analizar las formas en que organismos de derechos humanos durante la dictadura, el Estado y entidades privadas del presente postdictatorial, han registrado las violaciones a los derechos fundamentales (Bernasconi et al., Guía 9),

5 Todo el desarrollo de estos conflictos en torno a los archivos de derechos humanos pueden ser desarrollados en S/A 2014.

6 https://memoriayderechoshumanosuah.org/tecnologias-politicas-de-la-memoria-3/ 
plantea comprender a los archivos de derechos humanos como "tecnologías de resistencia" frente a la violencia estatal (Bernasconi, "Political" 24-25). De acuerdo a los responsables del proyecto, el entendimiento de los archivos como tecnologías políticas permitirá comprender cómo las vulneraciones a los derechos humanos están relacionadas con las prácticas y artefactos que las documentan y preservan, en tanto se trata de una labor de gestión política de catástrofes, conservando elementos documentales que contribuyen a impedir el olvido y la impunidad (Bernasconi, "Del archivo" 87). Finalmente, en términos de acción colectiva de rescate y promoción de estos acervos, desde 2011 existe la Red de Memoria y Derechos Humanos (RAMDH), ${ }^{7}$ un colectivo que agrupa a los principales archivos documentales ${ }^{8}$ y que tiene por objetivo generar instancias de reflexión y participación en torno a la conservación, organización, descripción, puesta en valor, acceso y uso de los documentos y materiales almacenados.

\section{REPRESORES, LOS ARCHIVOS Y LA "DUDA"}

Groppo señala que existe una relación directamente proporcional entre mayor acceso a los archivos de la represión y más alta democratización de las sociedades post-conflicto, y reconoce que el desafío principal en materia de enfrentamiento del pasado es el conocimiento público de los acervos generados por los órganos represores (Groppo 38). Si se considera que, por lo general, el acceso a esta documentación es altamente improbable debido a su destrucción por parte de los agentes represores o su ocultamiento durante la post-dictadura, el debate político por la figuración pública de estos acervos implica la introducción de la discusión acerca de los perpetradores, las tensiones sociales acerca de su presencia en el espacio público y la comprensión del "archivo" como un elemento en constante revisión.

7 https://ramdh.cl/

8 Actualmente, son parte de esta red: Archivo Federación de Estudiantes de la Universidad de Chile, Archivo de Documentación Gráfica y Audiovisual de la Universidad de Santiago de Chile, Comisión Chilena de Derechos Humanos, Corporación Parque por la Paz Villa Grimaldi, Fundación de Ayuda Social de las Iglesias Cristianas, Fundación de Protección a la Infancia Dañada por los Estados de Emergencia, Fundación Salvador Allende, Fundación de Documentación y Archivo de la Vicaría de la Solidaridad, Londres 38 Espacio de Memorias, Museo de la Memoria y los Derechos Humanos y Fundación Víctor Jara. 
Respecto del estudio sobre los represores en América Latina, ${ }^{9}$ este es un campo que presenta dos encuadres. Por una parte, existe un cuerpo analítico que aborda el ámbito militar en relación a los golpes de Estado y la militarización de la región en la década de 1960 y 1970 (Victoriano 179-180), en el marco del abordaje de la Doctrina de Seguridad Nacional (Leal 81-82), centrando su atención en el análisis de los regímenes dictatoriales de aquel periodo (O’Donnell 75-76) y el auge del "nuevo autoritarismo" (Lechner 124) y que, en el presente, se concentra en el estudio de las relaciones entre las Fuerzas Armadas y los sistemas políticos democráticos (Kruijt y Koonings 10-12). Por otro lado, en los últimos años se ha desarrollado una corriente académica en el estudio de la historia reciente argentina que propone un nuevo tratamiento en el análisis de la represión, a través del abordaje relacional de las prácticas, ideologías, instituciones, actores y discursos, estableciendo vínculos y continuidades entre las violaciones a los derechos humanos del pasado y las existentes en el presente (Águila et al. 8-9; Águila 1-2). En el marco de esta última dimensión analítica, se ha concretado un espacio de problematización del campo de la memoria acerca de los represores, que plantea revisar el discurso y la presencia, en tanto acto performativo, de los agentes en el ámbito público. Salvi, en este sentido, ha identificado las principales controversias asociadas a las declaraciones públicas de los perpetradores, señalando que, a pesar de reconocer a priori que sus palabras contienen solo falsedades, su "acto de habla" se posiciona como un hecho político-simbólico que remece la democracia (Salvi, "Los represores" 2829). En tal sentido, dos cuestiones son fundamentales respecto de la voz de los perpetradores. Por un lado, el problema de no otorgar legitimidad social a las

9 Considerando el objetivo de este escrito, se concentró la atención en el abordaje académico del campo de los estudios de la memoria en América Latina relacionado con los represores. Para una revisión general acerca de las investigaciones sobre los perpetradores, revisar el trabajo de Jon Elster, en el que se abordan las tipologías de criminales de los regímenes totalitarios del siglo XX de Alemania e Italia y de los diferentes colaboracionistas de la Francia ocupada por los nazis, así como las construcciones argumentales de estos sujetos (Elster 162-170). En general, el tratamiento académico acerca de la figura de los represores aparece sometido al estudio sobre las Fuerzas Armadas, especialmente en las investigaciones sobre transiciones a la democracia desde regímenes autoritarios. En los estudios sobre esta materia de O’Donnell y Schimitter, los autores analizan a los militares como un actor político que debe ser desactivado, mediante reformas institucionales, programas formativos y negociación, con el objetivo de conseguir una transición a la democracia sólida, libre de riesgos de regresiones autoritarias (O’Donnell y Schimitter 6769). Un aspecto que, en este sentido, no parece generar dudas es el creciente interés existente por comprender a aquellos sujetos responsables de las violaciones a los derechos humanos, ya sea con un sentido pedagógico (Gryglewski 22-26), o con una intención genérica sobre sus biografías (Orizo). 
versiones que proponen los victimarios, siendo este un asunto que implica la pregunta acerca de si es posible, inicialmente, concederles un espacio de habla (Feld y Salvi 8). Por otra parte, la controversia más importante es la veracidad, considerando la imposibilidad de la sociedad para definir parámetros que determinen si los dichos son auténticos (Feld y Salvi 9).

En Chile, la voz de los represores ha generado controversias relevantes en relación no solo a los contenidos de sus palabras, aun cuando se ha podido constatar su falsedad, sino que, sobre todo, por el impacto social de su presencia. En el pasado dictatorial, uno de los principales episodios en esta materia ocurrió en 1984, cuando el exagente del Comando Conjunto Andrés Valenzuela, decidió abandonar el organismo represor y otorgar su testimonio acerca de las prácticas criminales en las que participó y/o de las que fue testigo. La publicación de sus declaraciones en la revista Cauce generó reacciones tanto en el gobierno autoritario, como en los organismos de derechos humanos de la sociedad civil. ${ }^{10}$ En postdictadura, eventos de esta naturaleza fueron más frecuentes, a través de publicaciones y declaraciones en medios de comunicación, aunque con el objetivo de defender y justificar las acciones represivas. Algunas de las principales acciones en esta materia ${ }^{11}$ fueron la entrevista concedida por Augusto Pinochet en noviembre de 2003 al medio estadounidense Canal 22 de Miami, que conllevó la reapertura del caso judicial en su contra, y las declaraciones del ex director de la DINA, Manuel Contreras, en un reportaje de Canal 13 sobre la cárcel para exmilitares condenados por violaciones a los derechos humanos "Penal Cordillera", emitido en 2013, que posibilitó que el gobierno del entonces presidente Sebastián Piñera decidiera el cierre de este recinto. En ambas alocuciones, tanto Pinochet como Contreras reforzaron la tesis de defensa del régimen dictatorial y la exculpación de la violencia, proporcionando este último, información errónea sobre el destino de los detenidos desaparecidos. Esta afirmación se condice con los antecedentes, también falsos, que las Fuerzas Armadas otorgaron durante la Mesa de Diálogo.

Antes de aquellas entrevistas, el 18 de mayo de 1995 se emitió en la cadena de televisión estadounidense Univisión el testimonio de Osvaldo Romo Mena, exagente civil de la agrupación Halcón I de la Brigada Caupolicán de la DINA, quien, abiertamente, habló de la tortura aplicada a los opositores en dictadura. En la entrevista, registrada en la Cárcel Pública, recinto donde Romo cumplía condena desde 1992, el exagente detalló las sesiones de tortura

10 Para una revisión desde el presente del impacto de este hecho, revisar González.

11 Para una revisión completa de los episodios en que los represores han emergido en el espacio público con impacto social y político, revisar Jara y Aguilera. 
y los mecanismos de desaparición y lamentó que los organismos represores no lograran exterminar a toda la oposición a la dictadura. ${ }^{12}$ En Chile, la publicación de la entrevista fue recibida de manera crítica. Guzmán señala que este hecho significó una desviación en la política transicional, basada en el acuerdo tácito de no abordar políticamente las violaciones a los derechos humanos ${ }^{13} \mathrm{y}$ marginar la discusión acerca de la tortura sistemática. ${ }^{14}$ Por un parte, la oposición al gobierno del entonces Presidente Eduardo Frei Ruiz-Tagle, cuestionó la autorización para la grabación del testimonio al interior del recinto penitenciario, mientras que, por otro lado, el Ejército criticó al Gobierno por permitir su difusión (Guzmán, Romo 228-229).

Sin embargo, también han existido episodios en que la voz pública de exagentes ha mermado los "pactos de silencio" existentes, denunciando a otros oficiales. Los dos principales hechos, en este sentido, fueron representados por exconscriptos: la denuncia en 2012 sobre Pedro Barrientos Núñez por el asesinato de Víctor Jara y la confesión en 2015 que desmintió la versión de la dictadura respecto del Caso Quemados de 1986. Una iniciativa novedosa en este campo, aunque con evidentes diferencias en relación a los sujetos que la componen, es el surgimiento del colectivo "Historias desobedientes Chile", ${ }^{15}$ una agrupación de hijos e hijas de exagentes condenados por violaciones a los derechos humanos. Reconociendo la responsabilidad penal de sus familiares en los actos criminales cometidos en dictadura, los integrantes de esta organización realizan acciones

12 El sitio web de The Clinic publicó parte de esta entrevista en 2012. En un fragmento de la declaración de Romo, este señala: "Yo no dejaría periquito vivo. Todo el mundo pa' la jaula. Ese fue un error de la DINA. Yo se lo discutí hasta última hora a mi general: 'no deje a esa persona viva, no lo deje libre'. Ahí están las consecuencias".

13 La tesis de la disociación entre la transición política y el tratamiento de las violaciones a los derechos humanos durante los primeros gobiernos post-dictadura ha sido abordada, entre otros por Garretón.

14 Hasta antes de la publicación del Informe de la Comisión Nacional de Prisión Política y Tortura en 2004, el abordaje de las violaciones a los derechos humanos desde la perspectiva de los sobrevivientes había sido una problemática no abordada políticamente, aun cuando la magnitud de la misma ya se reconoció, aunque sin datos concretos, en el Informe de la Comisión Nacional de Verdad y Reconciliación de 1991. En 2001, sin embargo, un episodio públicamente conocido remeció a la opinión pública nacional al presentar el caso de un sobreviviente de tortura que debía convivir con su torturador en su lugar de trabajo. El caso de Felipe Agüero y Emilio Meneses en la Universidad Católica fue recogido en el libro editado por Patricia Verdugo De la tortura no se habla.

15 Originalmente, el colectivo "Historias desobedientes" surgió en 2017 en Argentina, agrupando a seis familiares de exagentes represores con el objetivo de aportar al debate, desde la crítica y denuncia, que se propició en el país trasandino como resultado de la iniciativa conocida públicamente como "2 por 1". Esta información fue proporcionada por Leslie Araneda en el Seminario “Apropiaciones del pasado. Reconfigurando lo común”, realizado en el Museo de la Memoria y los Derechos Humanos el martes 19 de noviembre de 2019. 
de denuncia y solidaridad con las víctimas. Por otra parte, dando cuenta de la dinámica situación de los archivos de derechos humanos y su relación con los represores, en 2017 ocurrió un caso particularmente disruptivo e inédito. El exgeneral del Ejército Juan Emilio Cheyre, encontrándose investigado por violaciones a los derechos humanos ocurridas en dictadura, solicitó a la Fundación de Documentación y Archivo de la Vicaría de la Solidaridad información acerca de su posible mención en expedientes de aquel acervo que lo pudieran relacionar con delitos de lesa humanidad. El organismo respondió señalando que no había referencias que lo involucraran. La situación generó una crisis al interior de la Fundación, pues sí existían menciones a Cheyre en reiterados casos relativos a víctimas de la ciudad de La Serena. El error fue posteriormente corregido, obligando a la Fundación a generar un nuevo protocolo, por medio del cual se prohíbe la comunicación directa, en el marco de procesos judiciales, con agentes investigados, señalando que toda la documentación debe ser canalizada a través de los Tribunales de Justicia.

En términos académicos, el campo de los represores en Chile es un asunto relativamente novedoso. Desde una perspectiva general, Jara y Aguilera (2017), a partir de la revisión de algunos episodios claves en que los victimarios han permeado los marcos sociales respecto del entendimiento del pasado, abordan cómo la figura de los perpetradores representa un desafío para los estudios contemporáneos de la memoria, tensionando la presencia única de la "víctima" como centro de atención de las investigaciones. Los trabajos de Verónica Valdivia, por otro lado, han significado aportes relevantes al estudiar la evolución del pensamiento político de las Fuerzas Armadas, identificando las principales pugnas doctrinarias en relación a la hegemonía de determinados proyectos sociales (2003), el avance y desarrollo del pinochetismo entre la población (2010) y las interrogantes acerca de la subordinación militar al poder civil en la postdictadura (2019). Recientemente, se ha generado un creciente espacio de debate político acerca de la representación pública de los represores, en particular, sobre cómo incorporarlos en relatos y soportes materiales, tanto en museos (Mallea y Meirovich), como en sitios de memoria (Rebolledo y Sagredo). Por último, desde una perspectiva escasamente abordada, destaca el trabajo de Lazzara (Civil Obedience) acerca de los privados que apoyaron el régimen de Pinochet, proponiendo un enfoque de estudio que comprende cómo los ciudadanos se involucran cultural y políticamente con las prácticas autoritarias. Estudios como este se enmarcan en una problematización que permite distinciones entre civiles y militares como agentes de la represión dictatorial (Sepúlveda) y que, a la fecha, ha generado controversiales investigaciones, principalmente periodísticas y/o testimoniales, acerca de antiguos militantes que, luego de ser detenidos, pasaron 
a formar parte de los organismos represivos ${ }^{16}$ y agentes no militares que han reconocido públicamente las acciones criminales de la dictadura. ${ }^{17}$

Considerando todo lo anterior, una interrogante clave es el lugar de la voz de los represores en los archivos. ${ }^{18} \mathrm{Si}$ bien, de manera directa, este desafío no ha sido parte del debate sobre los acervos de derechos humanos en Chile, el planteamiento de la cuestión tensiona las definiciones tradicionales del "archivo". En tal sentido, la propuesta del "giro del archivo" puede permitir distinguir dos asuntos relevantes respecto de los retos contemporáneos. Por una parte, reconocer que es posible superar la tradicional noción del archivo como un "instrumento de hegemonía" de la historia oficial (Zeitlyn 462) y generar acercamientos a una definición post-colonial a partir de la cual los documentos se estudien mediante un enfoque etnográfico (Stoler 94). Por otro lado, reparar en las formas en que la información contenida en los acervos fue producida y organizada, prestando atención tanto a los principios con que fueron construidos, como los efectos contemporáneos y futuros de las prácticas de registro (Bernasconi, "Del archivo" 73-74).

No obstante, aun reconociendo el carácter multidisciplinar del archivo para afrontar desafíos, permanece una de las principales limitantes para el campo de la archivística: la duda respecto de la legitimidad y pertinencia de otorgar un espacio a la voz de los represores. Esta "duda" puede significar pugnas en la propia definición del archivo, en su ordenamiento tanto temático, como institucional, considerando que se trata de un espacio que implica decisiones complejas respecto de jerarquías, criterios y clasificaciones. ${ }^{19}$

16 Se trata del libro testimonial El Infierno de Luz Arce, quien fue militante del Partido Socialista y luego de ser detenida por la DINA, colaboró con este organismo. También, en esta categoría están las investigaciones sobre Miguel Estay, militante del Partido Comunista que colaboró con los organismos represores luego de su captura, que han sido desarrolladas por CIPER Chile (en particular por Francisca Skoknic con el título "Miguel Estay, El Fanta: Las razones de un verdugo" en 2007) y Nancy Guzmán (en su libro de 2016, El Fanta. Historia de una traición).

17 El principal exponente es el mediático caso de Jorgelino Vergara, conocido como "el mocito" de Manuel Contreras y de la DINA, cuyo testimonio acerca de los crímenes cometidos por este organismo, así como por la dictadura en general, fue recogido en el libro del periodista Javier Rebolledo La danza de los cuervos: el Mocito y el destino final de los detenidos desaparecidos, lanzado originalmente en 2012 y reeditado con el título señalado en 2016.

18 De manera indirecta, Dinges y Kornbluh han propuesto estrategias para estudiar la documentación de los organismos represivos de gobiernos dictatoriales. Si bien sus planteamientos no se ajustan a documentos generados directamente por un exagente, se reconoce una fórmula necesaria para el abordaje de información dudosa. La estrategia, en síntesis, consiste en prestar atención a las condiciones en que fue generada la documentación, chequearla críticamente mediante la triangulación de la información y sostener el criterio de saturación.

19 Pavez ha desarrollado la propuesta del cambio social en relación a los archivos, afirmando que las definiciones conceptuales y operativas de estos pueden impactar en el orden de las instituciones a las cuales pertenecen (Pavez 10-11). 
Particularmente, en referencia a las problemáticas asociadas a la "duda", el análisis propuesto por Joignant respecto de las políticas de memoria resulta clarificador e ilustrativo. El autor ha afirmado que estas políticas públicas están definidas a partir de dos asuntos que son resultado de las luchas sociopolíticas por la determinación de versiones sobre el pasado. En primer término, la verdad que estas son capaces de identificar, probar e instalar en el espacio público. Y, en segundo lugar, "la duda perpetua". Aquella duda respecto de hechos históricos fundacionales para la memoria contra-hegemónica (como la muerte de los expresidentes Salvador Allende y Eduardo Frei Montalva o del Premio Nobel de Literatura, Pablo Neruda), se habría posicionado como la condicionante principal respecto del alcance y sentido de las políticas de memoria, definiendo el cómo nos acercamos a las atrocidades, qué podemos plantear de estas en el presente y cuánto de todo lo que sabemos es validado socialmente como relato oficial. Desde esta perspectiva, tradicionalmente, en el abordaje de archivos de organismos represores, la permanencia de las dudas sobre la información contenida se tiende a resolver mediante la pericia judicial. No obstante, a pesar de que el trabajo jurídico logra, mediante el sistema de investigación del derecho penal, la "verdad procesal", cuando se trata de documentación relativa a los represores se produce una disociación jerarquizada entre la "verdad histórica", asociada al testimonio probatorio de las víctimas (Rincón) y la palabra de los victimarios, considerada falaz.

Por cierto, en este marco analítico acerca de la relación entre veracidad histórica y relato testimonial, es importante precisar que, si bien el testimonio sobre violaciones a los derechos humanos ha permitido que sectores subalternos puedan hablar por sí mismos, obteniendo legitimidad y espacios dentro de los debates académicos y procesos judiciales, y rescatando memorias postergadas o silenciadas (Strejilevich, El lugar 25), existen dos situaciones críticas. Por una parte, en el esquema legislativo de esclarecimiento de la verdad, los sobrevivientes son considerados únicamente como testigos, limitando sus relatos a descripciones centradas en el acto criminal, es decir, en el secuestro, la tortura y la muerte o desaparición de otros, marginando su rol como actores políticos (Strejilevich, "El testimonio" 18). Por otro lado, el problema que se presenta ante este avance de lo testimonial al otorgarle a este un valor de verdad absoluta e irrefutable, lo que implica, necesariamente, analizar también los límites del testimonio en cuanto elaboración de conocimientos históricos (Ruiz), teniendo en consideración el contexto político y social que determina qué relatos validar y cuáles deben ser puestos en duda. 


\section{EL PARQUE POR LA PAZ VILLA GRIMALDI. BREVE HISTORIA}

El centro de detención, tortura y exterminio conocido como Villa Grimaldi operó entre 1974 y 1978, siendo uno de los enclaves represivos más importantes de la dictadura cívico-militar. En este se asentó la Brigada de Inteligencia Metropolitana de la DINA, el principal organismo de seguridad del gobierno autoritario, la cual, renombró el lugar como "Cuartel Terranova" (Salazar 97). Se estima que aproximadamente cuatro mil quinientas personas estuvieron recluidas en el sitio durante sus cuatro años de funcionamiento, de las cuales, doscientas cuarenta y una fueron asesinadas o hechas desaparecer. Comenzó a ser demolido a fines de la década de 1980, en el marco de la estrategia de ocultamiento de la dictadura, a través de la desaparición de los recintos represivos (Santos-Herceg 257-258).

Al mismo tiempo en que el lugar era arrasado, se organizó un colectivo de la sociedad civil denominado Asamblea Permanente por los Derechos Humanos, compuesto por vecinos del sitio, exdetenidos, familiares de víctimas, y comunidades cristianas, que buscaba frenar las acciones de demolición y recuperar el espacio para transformarlo en un recinto de memoria. Las presiones de la Asamblea lograron que, a fines de 1993, el Estado expropiara la propiedad a la empresa inmobiliaria que pretendía construir sobre el sitio un conjunto habitacional. En 1994, se produce el primer ingreso de la sociedad civil al lugar. El mismo año, el Servicio de Vivienda y Urbanismo convocó propuestas para el proyecto Villa Grimaldi, resultando seleccionada la alternativa del Parque por la Paz. Finalmente, en 1996, la Asamblea decidió la creación de una corporación privada sin fines de lucro (la Corporación Parque por la Paz Villa Grimaldi ${ }^{20}$ ), con el objetivo de institucionalizar la gestión del sitio de memoria. Un año después, se inauguró el Parque por la Paz Villa Grimaldi, nombre con el que es conocido desde entonces. ${ }^{21}$ En 2004, el sitio fue reconocido como Monumento Nacional, en la categoría de Monumento Histórico.

La Corporación Parque por la Paz Villa Grimaldi es una entidad privada sin fines de lucro que, por Decreto Exento $N^{\circ} 170$ del 17 de marzo de 2005 del Ministerio de Bienes Nacionales, es la encargada de gestionar y poner en valor el sitio de memoria Parque por la Paz Villa Grimaldi, ex 'Cuartel Terranova', orientando su quehacer a la promoción y defensa de una cultura de los derechos humanos al interior de la sociedad chilena. La Corporación está conformada por una asamblea de socios, los cuales, en su mayoría, son exdetenidos, familiares y agentes que participaron en el proceso de recuperación. De entre los socios, se escoge democráticamente cada dos años, un Directorio compuesto por un Presidente, un Vicepresidente, un Tesorero, un Secretario y tres directores. Para más antecedentes sobre la Corporación y sus actividades, se puede revisar su sitio web: www.villagrimaldi.cl.

21 Para profundizar en lo relativo a la historia de Villa Grimaldi, revisar: Corporación Parque por la Paz Villa Grimaldi (2017). 
A pesar de las profundas discusiones acerca del sentido del Parque por la Paz (Lazzara, "Tres" 131), entre los actores responsables de la administración del lugar existía un acuerdo general respecto de la necesidad de reconstruir lo ocurrido al interior de este. Fue así como un sector de los exprisioneros que participaban en la Corporación, acompañados de profesionales voluntarios del campo de las ciencias sociales, comenzaron a organizar los recuerdos sobre el antiguo centro de detención en búsqueda de lograr una configuración espacial de las características de las celdas y los principales espacios de tortura (Corporación Parque por la Paz Villa Grimaldi 73-76). En 2006, se inició una iniciativa inédita de elaboración de un archivo oral con los testimonios de los sobrevivientes y familiares de las víctimas del sitio (Sagredo), luego, en 2009, se conformó oficialmente el Área Educación, responsable de, entre otras labores, la realización de recorridos pedagógicos para las comunidades educativas que visitan el sitio (Dalla Porta) y en 2013, se estableció el Archivo Documental como un esfuerzo por preservar los expedientes tanto de la Corporación, como de la historia del lugar (Iduarte, "Implementación").

\section{EL ARCHIVO DOCUMENTAL DEL PARQUE POR LA PAZ VILLA GRIMALDI}

El Archivo Documental del PPVG es una instancia creada por la Corporación Parque por la Paz Villa Grimaldi con el objetivo de aportar a la reconstrucción histórica de este sitio en relación con la historia reciente de Chile, a través del rescate y puesta en valor de diversos registros documentales relativos a los períodos por los que ha transitado el recinto. Esta iniciativa nació el año 2013 gracias al financiamiento otorgado por el "Programa para América Latina de Bibliotecas y Archivos" de la Fundación Andrew W. Mellon. ${ }^{22}$ La determinación del lugar donde se emplazaría físicamente el Archivo Documental (AD) debió considerar la condición de Monumento Histórico que posee el sitio. Por lo tanto, una construcción dentro del espacio patrimonial no era posible, decidiéndose, finalmente, realizar la instalación de un contenedor adaptado para el resguardo de los documentos, con las características necesarias de seguridad y conservación, fuera del área reconocida como Monumento Histórico.

22 Este programa es una iniciativa de la Universidad de Harvard y la Fundación David con el Centro de Estudios Latinoamericanos, la que contempla una ayuda económica para fortalecer la investigación de estudios latinoamericanos destinados a archivos y bibliotecas que necesitan recursos para mejorar las condiciones de sus colecciones. 
En términos de estructuración, la construcción del $\mathrm{AD}$ se pensó buscando albergar de forma eficiente la documentación. A partir de estándares de conservación para el correcto resguardo, se garantizaría la permanencia de los documentos a través de su digitalización, asegurando, además, el respaldo de la información contenida, preservando el original. El formato digital del documento se ingresa en un software de consulta que se aloja en la página web del PPVG, facilitando su búsqueda a través de una adecuada organización en fondos, subfondos y series, todo lo cual entrega un orden lógico a los usuarios.

La documentación se divide en tres fondos que se diferencian en su contenido, uso y restricciones de acceso. Estos son:

- Fondo Histórico. Da cuenta de la historia de Villa Grimaldi, incluyendo el periodo previo al golpe de Estado, el tiempo de funcionamiento del "Cuartel Terranova", la fase de recuperación del sitio, hasta la actualidad. Este fondo es abierto al público, pudiendo acceder a los documentos directamente ingresando a la página web, visualizándose a través del software ICA-AtoM. Contiene documentos en diversos soportes (fotografías, folletos, planos, prensa), agrupados cronológicamente, lo que permite reconstruir la historia del sitio ligada al acontecer nacional..$^{23}$

- Fondo Administrativo. Contiene documentos producidos por la Corporación Parque por la Paz Villa Grimaldi, desde su creación hasta la actualidad. De esta manera, se resguarda la información institucional y se obtiene un acceso más rápido a los documentos de administración y gestión. Su uso y acceso es solo para los miembros de la Corporación, para las distintas actividades que se realizan dentro de los equipos de trabajo.

- Fondo Procesos Judiciales. Contiene expedientes judiciales de causas individuales y colectivas de víctimas de violaciones a los derechos humanos que estén relacionadas con Villa Grimaldi. Forma parte de este fondo también la colección "Perpetradores", cuya descripción se abordará en el apartado siguiente. Militar (1973-1977). Periodo de la Dirección de Inteligencia Nacional (DINA); Dictadura Militar (1978-1990). Periodo de la Central Nacional de Inteligencia (CNI); Villa Grimaldi: Recuperación del sitio (1991-1993); Construcción del Parque por la Paz Villa Grimaldi (1994-1996); Parque por la Paz Villa Grimaldi (1997-hasta la actualidad). 
Debido a su importancia histórica y testimonial, el AD es utilizado para realizar investigaciones de la historia reciente chilena, principalmente de la dictadura cívico-militar y del periodo de transición hacia la democracia, abordando temáticas como memoria e historia reciente, derechos humanos y patrimonio. Los usuarios son, en su mayoría, académicos, estudiantes e investigadores de diversas disciplinas de las Ciencias Sociales, así como de la Educación y las Artes. Los archivos son consultados también desde el interior de la Corporación, con el objetivo de realizar investigaciones y exposiciones ligadas a las temáticas antes señaladas. ${ }^{24}$ Así también, son utilizados como insumos para el desarrollo del guion de los recorridos pedagógicos que el Área de Educación realiza con comunidades educativas que visitan el sitio. Todo lo anterior le significa al AD ser una herramienta que permite la conexión generacional y la elaboración de conocimiento sobre el periodo dictatorial, con sentido pedagógico y público. Desde el punto de vista judicial, los documentos del AD comprenden valor documental como medio de prueba para ser utilizados en procesos judiciales que llevan a cabo contra violadores de derechos humanos. Esto está en directa relación con el derecho a la verdad, a la justicia y a la reparación de las víctimas, ayudando a evitar la impunidad por crímenes de lesa humanidad.

Como se mencionó anteriormente, la mayoría de los archivos de derechos humanos chilenos pertenecen a organizaciones no gubernamentales, por lo que es necesario que entre estas agencias se generen espacios de transferencia de conocimientos y experiencias, con el objetivo de abordar en conjunto los nuevos retos y necesidades que surjan. En términos de relaciones extra-institucionales, el AD del PPVG ha apoyado a diversas organizaciones de derechos humanos que solicitaron ayuda en materia de transferencias y acompañamiento, ya sea en la implementación de sus propios archivos (en casos en que están comenzando a ordenar su documentación y deseen conocer la forma en que en el PPVG se gestiona el catálogo y sus protocolos), como en situaciones que involucran a organizaciones consolidadas (las que, por falta de financiamiento, han visto cómo sus archivos permanecen sin actividad y desean retomarlos para resguardar

Unas de las más recientes iniciativas fue el proyecto "Peñalolén en la memoria. De historia popular y resistencia", instancia en que participaron diversas áreas de la Corporación Parque por la Paz Villa Grimaldi. El proyecto de investigación e intervención territorial buscó rescatar la memoria de la conformación de las poblaciones emblemáticas de Peñalolén, destacando la resistencia a la violencia de Estado durante la dictadura y la participación de vecinos y vecinas en las denuncias de destrucción de Villa Grimaldi y en la recuperación del lugar hasta transformarlo en un sitio de memoria. La investigación finalizó con una exposición y una publicación. Es posible acceder a este trabajo a través del siguiente link: http://villagrimaldi.cl/wp-content/uploads/2019/07/ Folleto_Penalolen_26.06.pdf 
y poner en valor). En esta labor, también se destaca la mencionada Red de Archivos de Memoria y Derechos Humanos.

Actualmente, el AD se encuentra en una etapa de sistematización, crecimiento y diversificación de sus acervos, contemplando la creación o adquisición de nuevas colecciones, referidas a Villa Grimaldi y a temáticas relacionadas. El objetivo es que estas sean utilizadas como fuentes para la elaboración de exposiciones y de proyectos de investigación ejecutados tanto por la Corporación como por usuarios externos a la institución, reforzando con esto su compromiso con el resguardo de la memoria de las violaciones a los derechos humanos y aportando a la lucha colectiva contra el olvido y el negacionismo.

\section{LOS CUADERNOS DE ROMO EN EL ARCHIVO DOCUMENTAL DEL PARQUE POR LA PAZ VILLA GRIMALDI}

\subsection{Reseña del torturador Osvaldo Romo y el origen de sus cuadernos}

Osvaldo Enrique Romo Mena fue, antes de formar parte de la DINA, un destacado dirigente poblacional durante el gobierno de la Unidad Popular. Militó en la Unión Socialista Popular (USOPO), participando en las elecciones parlamentarias de 1973, sin resultar electo. Su presencia en una serie de poblaciones de la comuna de Peñalolén, tales como Nueva La Habana y Vietnam Heroico, le proporcionó conocimiento sobre los principales dirigentes, en particular del Movimiento de Izquierda Revolucionaria (MIR), a quienes posteriormente identificó para que fueran detenidos y torturados, luego del golpe militar del 11 de septiembre de 1973. Durante la dictadura, Romo se incorporó a la DINA, participando en los grupos y operaciones que tenían como objetivo identificar y capturar al MIR (Cavallo et al. 41) manteniéndose activo en esta organización hasta fines de 1975, año en que parte a Brasil. Aun cuando no existe certeza sobre si Romo era un agente encubierto de la inteligencia militar antes del golpe de Estado, su rol como agente activo en las acciones represivas de la dictadura es un hecho extensamente documentado en los expedientes judiciales de la post-dictadura.

Con el retorno a la democracia comienza un lento y gradual proceso de investigación penal de las violaciones a los derechos humanos. Romo fue capturado en 1992 en Brasil, por orden del Poder Judicial chileno, en el marco de la investigación a cargo de la magistrado Dobra Lusic sobre la desaparición de Alfonso Chanfreau ocurrida en 1974. Luego de su deportación a Chile, fue recluido en la Cárcel Pública de Colina, condenado por delitos de tortura y 
secuestro. En 2000, fue trasladado a Punta Peuco, lugar donde permaneció hasta su fallecimiento, siete años después. Durante sus años de presidio, Romo redactó una serie de manuscritos, además de almacenar un conjunto de imágenes, fotos y recortes de periódicos. En 2006, el periodista Jorge Escalante, en reportaje para La Nación, accedió a algunos de estos cuadernos. Describiendo los manuscritos como de una escritura compleja de comprender, debido a los errores ortográficos y al tipo de redacción empleada, Escalante señaló que en sus textos Romo "No pide, pero busca el perdón de los desaparecidos, a quienes habla a veces en primera persona evocándolos, invocando su compresión y alabando su compromiso militante. También pretende el perdón de los sobrevivientes del MIR, cuya estructura clandestina dice haber llegado a conocer a la perfección para la DINA" (Escalante 1). El periodista identificó algunos patrones en los textos del exagente, reconociendo que, en general, existe delirio y desórdenes históricos y temáticos. Por una parte, es posible encontrar autodefensa, rechazando el actuar tanto de los jueces que lo han condenado, como de los sobrevivientes que lo denuncian. Por otro lado, existen referencias a situaciones de secuestro y tortura, así como de víctimas, que son descritas como "lamentables" (Escalante 3).

Todos estos documentos, almacenados en cajas luego de la muerte de Romo, fueron incautados por el juez Alejandro Solís, quien se encontraba investigando diversas causas de violaciones a los derechos humanos ocurridas en Villa Grimaldi. Si bien la intención era hallar evidencia sobre el destino de los detenidos desaparecidos, los cuadernos, al no contener información útil en ese ámbito, fueron desestimados prontamente como objetos sin valor judicial. Esta situación, sumada al retiro del magistrado Solís en 2012, propició que las cajas con los manuscritos y objetos de Romo pudieran ser revisadas por la sociedad civil. Así, con el objetivo de garantizar su correcta conservación y posibles consultas futuras, el Poder Judicial entregó a la Corporación Parque por la Paz Villa Grimaldi, en condición de comodato, las cajas de Romo a fines de 2012. ${ }^{25}$

\subsection{El ingreso al Archivo Documental de Villa Grimaldi}

De acuerdo al registro de ingreso del AD del PPVG, el conjunto de documentación recibida correspondía a:

25 El diálogo entre la Corte de Apelaciones y el PPVG en esta materia fue responsabilidad del Directorio de la Corporación de aquel momento, en comunicación directa con el juez Alejandro Solís. 
unos 2 metros lineales aproximadamente de documentos en su mayoría cuadernos escritos a mano con bolígrafo azul o negro, (...); cada cuaderno posee una o dos fotocopias de lo escrito, además escritos de Romo en folios sueltos y copiadas dos veces. Hay otra documentación que corresponde a cartas algunas cerradas, recortes de diarios sueltos y otros puestos en carpetas pegados en hojas de oficio, presumiblemente recopilados por Romo, además hay 4 agendas con notas. Otros documentos corresponden a: cartas, fotos, postales, todos de carácter personal. Se encontraron estampas religiosas, algunas adhesivas, calendarios de bolsillo, etc. (Iduarte, "Implementación" 19).

La catalogación se inició utilizando el criterio del ordenamiento cronológico, sin embargo, no fue posible continuar debido a que muchos cuadernos presentaban fechas reiteradas y, además, las carpetas recibidas del Poder Judicial poseían folios que no estaban relacionados con las fechas de los escritos. Un segundo reto en materia archivística fue el contenido general de las cajas. Considerando la diversidad de objetos, se elaboró una organización preliminar conformada de la siguiente manera: "a) Cuadernos con relatos: (...) a.1.- fechados, a.2.- no fechados; b) Relatos en hojas sueltas; c) Documentos y cartas con amigos y familiares, c. 1 cartas familiares, c. 2 cartas de amigos, c.3 fotos, c. 4 imágenes religiosas y textos religiosos; d) Agendas (5); e) Recortes de periódicos; f) carpetas con copias de todos los relatos" (Iduarte, "Implementación" 19-20).

Si bien el contenido de los manuscritos ya había sido chequeado por el juez Solís sin resultados positivos desde el punto de vista penal, esto no determinaba que los cuadernos no contuviesen información que pudiera ser significativa para exdetenidos y familiares de víctimas. Por lo tanto, una dificultad adicional en aquel momento fue el resguardo ético. El ingreso de esta documentación, en este sentido, representó un triple desafío: su conocimiento público (es decir, cómo presentarla), el tratamiento de su contenido y su lugar al interior de un archivo que contenía, principalmente, documentos asociados a víctimas y al trabajo de memoria y derechos humanos del sitio. En consideración de todo lo anterior, la Corporación decidió, por una parte, mantener esta documentación en reserva hasta no tener certeza, por medio de la catalogación completa, de todos los antecedentes dispuestos en los manuscritos. ${ }^{26}$ Por otro lado, dentro del

26 Información proporcionada a los autores por Roberto Fuertes, quien se desempeñaba como Coordinador del Área Museo de la Corporación Parque por la Paz durante el momento en que las cajas de Romo fueron recibidas. 
Fondo Procesos Judiciales, se creó el sub-fondo "perpetradores" con el objetivo de albergar los manuscritos y objetos de Romo como una colección, otorgándole una organización según el tipo de documento. A este fondo es posible acceder a través del catálogo en línea, aunque solo a la descripción de los documentos. Para su visualización, se decidió que sería necesaria la autorización de la/el encargada/o del Archivo, solicitando a los interesados que informen el motivo de su consulta. Si se requieren copias de algún documento, se debe elevar una solicitud al Directorio de la Corporación para recibir autorización.

\subsection{La mediatización y la catalogación acelerada}

En julio de 2015, se produjo un evento que modificó la estrategia de la Corporación en relación al tratamiento de esta documentación. El canal de televisión Chilevisión realizó un reportaje sobre Romo y solicitó al PPVG acceder a sus cuadernos. ${ }^{27} \mathrm{La}$ nota, titulada "Por primera vez se conocen los cuadernos del exagente de la DINA Osvaldo Romo", presentó imágenes de las cajas y su contenido, relatando el proceso por medio del cual la Corporación obtuvo estos documentos. La publicación de este reportaje generó un creciente interés social por los cuadernos, especialmente entre familiares de ejecutados políticos y detenidos desaparecidos, en cuyos secuestros Romo estaba implicado. En aquel momento, el AD desarrolló un método de consulta compuesto de tres etapas. Primero, se advertía a los interesados que los manuscritos no contenían información relevante en términos de evidencia sobre el destino de las víctimas, señalando que esta aseveración había sido otorgada por el Poder Judicial al momento de entregar las cajas. Segundo, se solicitaba que los interesados completaran una ficha de ingreso, titulada "Registro de consulta documentos en comodato", en la cual se identificaban datos personales, documentos solicitados y motivos de la consulta. Tercero, la revisión de la documentación se realizaba en una sala en la que se resguardaba, por medio de la presencia de un trabajador de la Corporación, que los documentos no fueran copiados sin autorización.

Durante el año 2015, luego del mencionado reportaje, se produjeron dieciséis consultas sobre las cajas de Romo. Los primeros interesados fueron los familiares de las víctimas, quienes, en conocimiento de la advertencia acerca de la ausencia de antecedentes novedosos sobre los casos, decidieron, de todos

27 Pizarro, Rodrigo, y Macarena Miranda. "Por primera vez se conocen los cuadernos del exagente de la DINA Osvaldo Romo". Chilevisión Noticias, 20 de julio de 2015, https://www.chvnoticias. cl/reportajes/por-primera-vez-se-conocen-los-cuadernos-del-ex-agente-de-la-dina-osvaldoromo_20150720/ 
modos, revisar los cuadernos. En reiteradas oportunidades, los familiares que chequearon los documentos declararon que el motivo de su consulta era acceder a información sobre el caso de su pariente, sin embargo, al finalizar su visita, reconocían estar conscientes de que su asistencia al archivo era "simbólica". ${ }^{28}$ Los documentos fueron revisados, además, por estudiantes de historia y periodistas, quienes estaban interesados en rescatar antecedentes sobre la DINA para conformar investigaciones sobre las violaciones a los derechos humanos en Chile. También accedieron a los materiales, profesionales de la Unidad Especial de Identificación Forense del Servicio Médico Legal e investigadores de la Brigada de Derechos Humanos de la Policía de Investigaciones. ${ }^{29}$ Ambas consultas solicitaron retirar copias de algunos fragmentos de los cuadernos, situación que fue resuelta mediante el escaneo de las secciones requeridas, las cuales fueron impresas. Para retirar las copias, los profesionales solicitantes debieron firmar un protocolo de recepción, documento que señalaba que la Corporación PPVG quedaba exenta de responsabilidades por el eventual uso de las reproducciones otorgadas.

La creciente demanda social por acceder a estos archivos determinó que el $\mathrm{AD}$ debiera concentrar sus esfuerzos en finalizar rápidamente la catalogación de toda la documentación de Romo. La encargada del AD de aquel momento, Vanessa Figueroa, con apoyo de algunos estudiantes, logró digitalizar los cuadernos en tres meses, dedicándose exclusivamente a esta labor. Según Figueroa, existieron tres asuntos críticos en el proceso de trabajo sobre los documentos de Romo. ${ }^{30}$ Por una parte, al ser imposible, como se señaló anteriormente, la utilización del criterio cronológico para la ordenación de los cuadernos, el trabajo archivístico se rigió por la revisión de sus contenidos. Sin embargo, tal como había indicado Escalante, los manuscritos presentaban una escritura deficiente e ideas repetitivas, por lo cual se tornaba difícil encontrar la idea central para su ingreso al catálogo. Los relatos regresaban frecuentemente sobre los puntos de inicio, describiendo los mismos hechos en reiteradas ocasiones, en algunos párrafos había palabras o líneas desaparecido le declaró a uno de los autores que tenía certeza de no encontrar antecedentes nuevos en aquellos documentos, pero que sentía la necesidad de revisarlos como una forma de cumplir con su deber hacia su hijo de agotar todas las instancias.

29 En la consulta del Servicio Médico Legal, el motivo de la revisión no fue explicitado, solo se mencionó que se trataba de una investigación oficial. En el caso de la Policía de Investigaciones, se declaró que el tema de consulta era la investigación por los casos de violaciones a los derechos humanos de Carmen Bueno, Jorge Müller, Francisco Núñez y Francisco Aedo.

30 Información proporcionada a los autores por Vanessa Figueroa, encargada del Archivo Documental de la Corporación Parque por la Paz Villa Grimaldi entre 2015 y 2017. 
en portugués, no había puntos y aparte en series de páginas y no existían fechas. Por otra parte, entre las personas involucradas en la catalogación existía una importante tensión emocional originada no solo en la distancia ideológica que había respecto de un exagente, sino que en la revisión constante de contenidos que buscaban exculpar y matizar las violaciones a los derechos humanos. Si bien Romo en sus cuadernos se refiere a las operaciones de secuestros que la DINA realizó, principalmente, en los centros de detención de Londres 38, Villa Grimaldi y Venda Sexy, su narración se orienta a responsabilizar a otros agentes de las acciones criminales, expresando lamentaciones por las muertes de los militantes a quienes decía conocer. Esta postura coincide con las declaraciones judiciales de Romo, en las que reconoce los hechos criminales y da cuenta de las acciones y culpabilidades de otros. ${ }^{31}$

Todo lo anterior determinó que el proceso de catalogación fuera más lento de lo habitual e involucrara un importante desgaste físico y emocional en quienes estuvieron relacionados con esta documentación. ${ }^{32}$ Esta última situación representa algunos de los principales desafíos en el trabajo sobre el testimonio de los perpetradores, sobre todo, desde un sitio de memoria. En este sentido, las dificultades señaladas por Salvi respecto tanto de la disponibilidad y accesibilidad de fuentes escritas y orales asociadas a la represión, como de las controversias acerca de la circulación y uso de la palabra de los represores como fuente histórica (Salvi, "Los represores" 36), son sobrepasadas por las cargas afectivas de los sujetos comprometidos en el trabajo de los sitios de memoria. En un estudio sobre la conservación de estos lugares, D’Ottavio reconoce que las decisiones sobre la preservación y restauración responden, en gran medida, a factores emotivos y políticos de los profesionales, en consideración del valor histórico y simbólico de los sitios, así como de sus usos públicos en materia de reparación y educación (D’Ottavio 71-72).

Con todo, la catalogación de los documentos de Romo finalizó en el año 2017 con la digitalización de todos los documentos. Los cuadernos y demás objetos originales pasaron a ser resguardados, y para consulta pública se permite el acceso a los documentos escaneados.

31 En la declaración judicial por las desapariciones de Martín Elgueta Pino y María Inés Alvarado Börgel de 1993, Romo señaló que "Estimo que el General Manuel Contreras y su grupo tienen que haber sabido cuál fue el destino final de los desaparecidos, sin que ellos hayan intervenido en la acción misma de hacerlos desaparecer, acción que creo que fue ejecutada por la 'contra inteligencia', formada por personas, capitanes, hasta el grado de mayor (...)”. (citado en Guzmán 30)

32 Vanessa Figueroa manifestó a los autores que para abordar los cuadernos de Romo fue necesario "entrar en ese mundo y encerrarse", señalando que se trataba de temas difíciles que le generaban malestar. Existiendo, según la profesional, una "carga profesional", en el marco de la cual, el desafío es "no involucrarse". 


\subsection{Principales contenidos controversiales}

En este apartado se muestran algunos fragmentos de los contenidos de los cuadernos de Osvaldo Romo. Los autores decidieron incluir una muestra mínima de las palabras del exagente en consideración de la precaución de no exponer en extenso una declaración falaz que pueda significar una apertura para el cuestionamiento al testimonio de víctimas y familiares. Sin embargo, se describen algunas de las principales controversias recogidas de la lectura completa de los manuscritos, con el objetivo de que los investigadores interesados en acceder a estos escritos puedan conocer las dificultades éticas y académicas más importantes del trabajo con este tipo de material.

Escritos de forma errática, los cuadernos de Romo mencionan muchos nombres, fechas, sucesos, dichos y referencias al comportamiento de agentes policiales y de víctimas de la violencia estatal. Sin embargo, el exagente no aclara los delitos cometidos, sino que utiliza estos escritos para otorgar su versión de los hechos acaecidos y, sin duda, para eludir su responsabilidad. La complejidad de los contenidos de este acervo no solo tiene que ver con la naturaleza del generador de los escritos, un represor condenado por crímenes de lesa humanidad, sino que con la evidente falsedad expresada. Estas características de los cuadernos determinaron que el $\mathrm{AD}$ definiera todas las particularidades y exigencias antes señaladas al momento de acceder a esta documentación, tomando resguardos sobre las dudas y los dilemas éticos asociados al manejo de la información.

Una muestra de la particular condición de los contenidos de los cuadernos de Romo es la notoria y constante negativa respecto tanto de la participación en cualquier situación relacionada con las violaciones a los derénos humanos, como del conocimiento de las mismas: “(...) la señora madre de Aníbal, ella sí estuvo varias veces conmigo en el tribunal y en la fiscalía, ahora yo lo siento mucho, yo no tuve nada que ver con el Aníbal, no podía darle ningún tipo de noticia y se lo dije a la señora madre". (Romo, s.f). Como se observa en este fragmento extraído de uno de los cuadernos, Romo afirma no tener ningún tipo de relación con lo sucedido con un detenido desaparecido (algo que se reitera en distintos cuadernos y con diferentes víctimas, más o menos, con las mismas palabras), y además, lamenta no tener información para los familiares. Es frecuente también hallar intentos por demostrar cercanía y buenas relaciones con las personas que estaban a su alrededor, en especial con los detenidos. Estos datos, sumados al permanente desconocimiento de su participación en los hechos de secuestro, torturas y desapariciones de personas, dan cuenta de una posición de auto-defensa generalizada. Si bien su forma de escritura es errática, permite, a través de una lectura extensa, dilucidar cómo intenta dar validez a sus escritos 
como vivencias reales. Romo presenta su narrativa como experiencias propias y, aunque reconoce que estas pueden ponerse en duda por los lectores, él a menudo las reafirma como verdaderas: “(...) realizar una buena verídica historia, esto porque algunos pueden decir que es ficticia, si, fantasía, pero no, esto es verídico si me refiero y puedo decir que esto es una real historia realizada del ámbito de la vivencia". (Romo, s.f).

El problema de la legitimidad y la autenticidad de sus propias palabras era un tema importante para Romo, tal como se evidencia en la cita antes expuesta. En relación con este asunto, otro elemento que se reitera en los cuadernos es el pleno convencimiento de Romo acerca de que estos escritos serán en el futuro investigados y utilizados para conocer el período de la dictadura cívico-militar chilena, destacando la validez de su testimonio como fuente histórica. En este sentido, en la actualidad, resulta evidente que la figura de Romo ha producido tensión e incomodidad tanto en investigadores, como en activistas de los derechos humanos, ${ }^{33}$ generando en la práctica, sentimientos de escepticismo e ilegitimidad. ${ }^{34}$ Esta situación se expresa en el dilema que el $\mathrm{AD}$ experimentó en esta materia. Si bien, la opción de invisibilizar y no entregar ninguna plataforma que permita que el represor pueda hablar no fue una alternativa mayoritaria, tampoco, en los hechos, existía una metodología definida en el PPVG acerca de cómo investigar documentación redactada por un exagente. ${ }^{35}$

Por último, la revisión completa de los cuadernos permite reforzar la información proporcionada por el juez Solís acerca de la ausencia de antecedentes novedosos o relevantes respecto de los contenidos asociados al secuestro, tortura y desaparición. El AD, al procurar no ingresar en la discusión de la veracidad o falsedad de las declaraciones expuestas en los manuscritos, permite que la

33 Guzmán describe la entrevista con Romo de la siguiente forma: "Más de cuatro horas duró la grabación de la sesión (...) Romo estaba nervioso y a ratos molesto, su cuerpo expelía ese hedor parecido al amoníaco que da la orina descompuesta, lo que hacía más insoportable la situación. (...) El final llegó cuando Romo se negó a seguir hablando (...). Para mí fue un alivio pensar que era la última vez que estaría en ese lugar, que ya no volvería a mirar al 'Guatón Romo'” (Guzmán, Romo 227).

34 En el citado reportaje de Chilevisión acerca de los cuadernos de Romo en el PPVG, al momento de ser consultados por la experiencia emocional de ser depositarios de este material, diversos representantes del sitio manifestaron sensaciones controversiales asociadas al rechazo y la conmoción.

35 En una investigación en curso desarrollada conjuntamente por la Corporación Parque por la Paz Villa Grimaldi y la Universidad Academia de Humanismo Cristiano acerca de la DINA y su relación con el incremento de poder político de Pinochet, se utiliza una propuesta metodológica novedosa sobre el tratamiento de fuentes relativas a organismos represivos basada en los principios de estudio propuestos por Dinges y Kornbluh. 
"duda" sobre los cuadernos de Romo intente ser resuelta por los investigadores. No obstante, se manifiesta expresamente la certeza relativa a que, a través de sus cuadernos, Romo intenta eludir su responsabilidad, matizando las violaciones a los derechos humanos ocurridas durante el periodo dictatorial, rechazando el actuar del sistema judicial, al que describe como un actor parcial que lo castiga, a su juicio, inmerecidamente: “(...) En este proceso yo estaba procesado sólo por capricho del actuario señor Aguilera del $4^{\circ}$ juzgado de San Miguel, yo fui amnistiado, es ridículo que un actuario que no conoce el tema, el es solo un vengativo". (Romo, s.f).

Esta breve muestra del testimonio plasmado por Osvaldo Romo en sus cuadernos, muestra la complejidad de este tipo de fuentes, principalmente, por las implicancias éticas en el uso de estos registros y el carácter instrumental que adquieren los recuerdos del exagente. Ante esto, el problema de la veracidad de manuscritos como estos queda como un debate difícil de superar. El esfuerzo analítico debe estar compuesto, al menos, por un abordaje que, por una parte, interprete la memoria de un hecho personal como una reconstrucción propia del testimoniante, pero que, al mismo tiempo, reconozca que la difusión y validación de estas narrativas depende de la organización del poder político del momento, el cual, según Calveiro se legitima gracias a un relato histórico coherente que construye una "verdad histórica" acorde con estas formas de poder.

\section{REFLEXIONES FINALES}

Los archivos de derechos humanos pueden ser entendidos como una parte clave de la batalla por la memoria que está siempre en construcción, considerando que los eventos traumáticos y sus rememoraciones tienen distintas resignificaciones, siendo necesarios tiempos de duelo y reflexión colectivos. En lo referido a los archivos de la represión, sin embargo, estas consideraciones adoptan una materialización diferente, no solo debido al hecho de que el acceso a estos es un asunto complejo, sino que, además, por la controversia política que generan los represores en el espacio público post-autoritarismo. En los estudios de la memoria del cono sur americano, la figura de los victimarios ha estado ausente. No obstante, su presencia ha sido permanentemente un elemento crítico desde el punto de vista social, ético e histórico.

En la experiencia analizada, la situación es particularmente compleja. Las cajas de Romo fueron recibidas por el sitio de memoria Parque por la Paz Villa Grimaldi en 2012, meses antes de la conformación oficial del Archivo Documental, lo que significó una presión directa para la pronta materialización 
del mismo. Al momento de su ingreso, este acervo representó desafíos preliminares asociados al conocimiento público de su entrada al PPVG, su tratamiento y su lugar de deposición definitivo. Estos asuntos propiciaron la creación del sub-fondo "Perpetradores" dentro del Fondo Procesos Judiciales, donde están ordenadas algunas causas ligadas a Villa Grimaldi. La reserva con que fueron tratados estos documentos, sin embargo, fue desarticulada como resultado de un reportaje televisivo que determinó que el Archivo Documental, y la Corporación en general, replantearan el lugar de estos manuscritos en el trabajo archivístico del sitio. Se reforzó la declaración institucional acerca de la ausencia de información relevante entre los cuadernos de Romo y se diseñaron fichas de registro y acceso, además de protocolos de consulta y reproducción de los manuscritos. Las solicitudes recibidas inmediatamente después del reportaje comunicacional representaron una prueba para el Archivo Documental en materia de tratamiento ético de consultas provenientes de familiares y víctimas. En términos de abordaje de los documentos, la presión por el creciente interés determinó también la concentración principal del Archivo Documental en la catalogación total de los contenidos de las cajas. El trabajo generó un profundo desgaste profesional y emocional como resultado de la lectura constante de afirmaciones negacionistas y exculpatorias.

Desde el punto de vista de los contenidos, la lectura transversal e integral de los cuadernos de Romo por parte del Archivo Documental, le ha permitido a este sostener que el acercamiento a este particular acervo representa un desafío clave para un sitio de memoria. Por una parte, es fundamental reconocer que en los manuscritos existen relatos que, intencionadamente, desconocen las violaciones a los derechos humanos, a través de lamentaciones por el destino de las víctimas, apariencias de cercanía emocional con los familiares y afirmaciones reiteradas de validez de la versión de los exagentes represores. Por otro lado, en conocimiento de la defensa generalizada de Romo respecto de sus acciones, es importante destacar que estos cuadernos podrán ser considerados en el futuro cercano como una fuente para el estudio del aparato represivo chileno. Aun cuando la veracidad de los textos es evidentemente inexistente, las dudas e interrogantes que estos comprenden son parte del desafío de las investigaciones en el campo de la memoria.

Si bien los cuadernos de Romo no contienen antecedentes que puedan ser considerados verídicos, pues en estos las interrogantes aún no son resueltas en su totalidad, sí es posible buscar entre sus contenidos elementos que permitan avanzar en investigaciones sobre la conformación y las estrategias de los grupos operativos y, especialmente, acerca de las creencias y valores de los perpetradores. Salvi, en este sentido, señala que, para materializar propuestas de esta naturaleza 
en el estudio sobre represores, es necesario diseñar instrumentos y técnicas investigativas que permitan "interrogar esos materiales", considerando que la aproximación generará "conocimiento parcial, incompleto, fragmentario" (Salvi, "Los represores" 26). El desafío del Archivo Documental de Villa Grimaldi está, justamente, en esa dimensión. Por cierto, se trata de un reto cuya extensión implica una profunda reflexión acerca del sentido del análisis del discurso de sujetos controversiales, determinando la necesaria aplicación de un giro respecto de la interpretación del hablante según su posición y en la estructura y proceso sociales. ${ }^{36}$ Del mismo modo, puede representar una oportunidad para repensar los límites de los estudios de la memoria, puntualmente, a lo referido a las reflexiones de Strejilevich ("El testimonio") respecto de la relación entre relato, veracidad y el lugar de los testimoniantes en el espacio público, más allá de la reducción de sus narrativas al campo de lo biográfico y judicial.

Sin embargo, un asunto extremadamente complejo en el archivo de Romo es que este no se trata de un acervo de la represión tradicional (como podrían ser documentos de seguimiento de víctimas u ordenanzas respecto del accionar represivo), a los cuales podría aplicarse los principios propuestos por Dinges y Kornbluh. Se trata de un conjunto de escritos personales de un exagente, elaborados durante el cumplimiento de su sentencia, los cuales fueron periciados por el Poder Judicial y marginados por la ausencia de información útil. Existiendo certeza judicial de la responsabilidad penal de este exagente, sus cuadernos no representan una fuente interesante acerca de posibles versiones disonantes en relación a las acusaciones en su contra. Pero su conservación en un sitio de memoria es un asunto que, en la experiencia del Archivo Documental del PPVG, genera dudas en dos dimensiones. Por una parte, por la posibilidad de otorgar un espacio a la memoria de un victimario en un lugar consagrado para la reparación simbólica de las víctimas. Por otro lado, por la inexistencia de una estrategia socialmente validada de investigación sobre los contenidos de los escritos. Ciertamente, el clivaje duda/veracidad, en los términos expuestos por Joignant respecto de las políticas de la memoria, proporciona a la discusión sobre los acervos de represores un elemento de desarrollo analítico que puede resultar vital para los estudios sobre la memoria: el contraste con el campo del relato testimonial de las víctimas. Flores y Bisama, en este sentido, sostienen que, más allá del extenso debate entre Historia y Memoria que condiciona al testimonio,

36 Una propuesta atingente, desde esta perspectiva, ha sido desarrollada por Canales, en lo que ha denominado "la escucha crítica", un aspecto del análisis del discurso que apunta a "interpretar lo comprendido", considerando la "situación existencial del hablante", particularmente su posición en la estructura social y contexto epocal (Canales 177). 
uno de los principales asuntos definitorios del análisis de la narrativa de los sobrevivientes, en tanto acto político, es la veracidad que los relatos comprenden de situaciones vivenciales que fueron negadas en el contexto dictatorial y han sido silenciadas en el periodo posterior (47-49). Si bien, las palabras de las víctimas pueden ser sometidas al chequeo histórico, considerando al hablante como "testigo", mientras que las narrativas de los perpetradores conllevan la duda del amparo del silencio institucional, el ejercicio de contraste es útil en la medida que permite identificar la "racionalidad" de los actos de tortura, sobre la base de la defensa del Estado y en la convicción de la impunidad.

En definitiva, el desafío del Archivo Documental en esta materia va mucho más allá del resguardo y puesta en valor de documentos vinculados a la memoria histórica y los derechos humanos. Implica aportar a la democratización de toda la información relativa al período dictatorial, sus actores y prácticas, generando, además, espacios y estrategias de acercamiento pedagógico a fuentes testimoniales diversas. El tratamiento didáctico de la documentación de Romo, basado en el contraste de fuentes y en el tratamiento ético de la información, puede significar una importante herramienta educativa acerca de los valores que deben ser promovidos para reforzar la convivencia democrática. Al mismo tiempo, la experiencia de estos cuadernos en el Parque por la Paz Villa Grimaldi puede ser un elemento a considerar en los estudios que cuestionan la noción tradicional del archivo, observando cómo estos no solo son necesarios para recibir y almacenar documentos, sino que conforman espacios de debate para el manejo de información controversial, garantizando su conservación y utilización por parte de generaciones futuras.

\section{REFERENCIAS BIBLIOGRÁFICAS}

Agüero, Javier. "El perdón inédito o un problema de (im) posibilidad. Apunte sobre los archivos de la transición chilena". Una memoria sin testimonio. Dilemas de la sociedad latinoamericana posdictadura, coordinadores Fedra Cuestas y Patrice Vermeren, Ediciones LOM, 2016, pp. 255-280.

Águila, Gabriela. "La represión en la historia reciente argentina: perspectivas de abordaje, conceptualización y matrices explicativas". Contenciosa, vol. I, no. 1, 2013, pp. 1-13. https://doi.org/10.14409/contenciosa.v0i1.5043 Águila, Gabriela et al. "Introducción". Represión estatal y violencia paraestatal en la historia reciente argentina: Nuevos abordajes a 40 años del golpe de Estado, coordinadores Gabriela Águila, Santiago Garaño y Pablo Scatizza, Universidad Nacional de La Plata, 2016, pp. 8-14. 
Arce, Luz. El Infierno. Tajamar, 2017.

Bernales Rojas, Gerardo. "El derecho a la verdad". Estudios Constitucionales, vol. 14 , no. 2, 2016, pp. 263-304. https://doi.org/10.4067/s0718-52002016000200009

Bernasconi, Oriana et al. Guía de Archivos de Derechos Humanos en Chile. Programa de Investigación Interdisciplinar en Memoria y Derechos Humanos, Universidad Alberto Hurtado, 2017.

---. "Las comisiones de la verdad en la batalla de la memoria: usos y efectos disputados de la verdad extrajudicial en Chile". Colombia Internacional, no. 97, pp. 27-55. https://doi.org/10.7440/colombiaint97.2019.02

Bernasconi, Oriana. "Del archivo como tecnología de control al acto documental como tecnología de resistencia". Cuadernos de Teoría Social, vol. 4, no. 7, 2018, pp. 68-92.

---. "Political Technologies of Registration and Denunciation of State Violence". Resistance to State Violence in Latin America, editora Oriana Bernasconi, Editorial Palgrave Macmillan, 2019, pp. 13-40. https://doi.org/10.1007/978-3-030-17046-2_2

Calveiro, Pilar. "Testimonio y memoria en el relato histórico". Acta Poét, vol. 27, no. 2, 2006, pp 65-86. https://doi.org/10.19130/iifl.ap.2006.2.204

Canales, Manuel. "Análisis sociológico del habla". Escucha de la escucha, coordinador Manuel Canales, Editorial LOM, 2014, pp. 171-188.

Cavallo, Ascanio, et al. La historia oculta del régimen militar. Ediciones La Época, 1998.

Corporación Parque por la Paz Villa Grimaldi. 20 años Sitio de Memoria Parque por la Paz Villa Grimaldi. Consejo Nacional de la Cultura y las Artes; Corporación Parque por la Paz Villa Grimaldi, 2017.

Dalla Porta, Constanza. "La trayectoria histórica de las visitas guiadas en Villa Grimaldi: síntesis y nuevas perspectivas". Cuaderno de Trabajos Educativos, vol. 9, 2017, pp. 13-34.

Da Silva Catela, Ludmila. "El mundo de los archivos". Justicia Transicional: Manual para América Latina, editor Félix Reátegui, Centro Internacional para la Justicia Transicional, 2011, pp. 381-406.

Dinges, John. The Condor years. How Pinochet and his allies brought terrorism to three continents. The New Press, 2004.

D’Ottavio, Adriana. "Apuntes sobre conservación material de sitios de memorias emplazados en CCDTyE de la Ciudad de Buenos Aires: desafíos y tensiones". Cuadernos del IDES, no. 32, 2016, pp. 57-76.

Elgueta, Gloria. "Secreto y acceso a la información pública". II Seminario Internacional Colonia Dignidad. Desafios frente a un archivo de la represión y la construcción de un sitio de memoria, editora Florencia 
Velasco, El Desconcierto, Asociación por la Memoria y los Derechos Humanos Colonia Dignidad, 2016, pp. 57-70.

Elster, Jon. Rendición de cuentas. La justicia transicional en perspectiva histórica. Katz Editores, 2006. https://doi.org/10.2307/j.ctvm7bdsq

Escalante, Jorge. "Romo desde las tinieblas". La Nación, 26 de febrero de 2006, http://www.archivochile.com/Chile_actual/16_hue_dict/chact huedict0021.pdf

Feld, Claudia y Valentina Salvi. "Presentación. Cuando los perpetradores hablan. Dilemas y tensiones en torno a una voz controvertida". Rubrica Contemporánea, vol. 5, no. 9, 2016, pp. 1-10.

Flores, Norberto y Adolfo Bisama. El relato testimonial chileno 1973-1989. RIL Editores, 2017.

Fondos y Colecciones del Archivo Documental de la Corporación Parque por la paz Villa Grimaldi 2019. Santiago, Chile: Colección Osvaldo Romo 2.3.1.1.3, 2.3.1.1.4, 2.3.1.1.5.

Garretón, Manuel Antonio. "La redemocratización política en Chile.Transición, inauguración y evolución”. Estudios Públicos, vol. 40, 1991. pp. 101-133.

Giraldo, Marta. "Archivos, derechos humanos y memoria. Una revisión de la literatura académica internacional". Rev. Interam. Bibliot. Medellín, vol. 40, no. 2, 2017, pp. 125-144. https://doi.org/10.17533/udea.rib.v40n2a02

González, Mónica. "Andrés Valenzuela: Confesiones de un agente de seguridad”. CIPER, 30 de septiembre de 2011.

Groppo, Bruno. "Dictaduras militares, archivos de movimientos políticos y sociales y archivos de la represión en América Latina". Archivos y memoria de la represión en América Latina (1973-1990), María Acuña et al., Ediciones LOM, 2016, pp. 31-54.

Gryglewski, Elke. “¿Por qué investigar sobre violadores de Derechos Humanos y autores de crímenes de lesa humanidad?". Pasados Inquietos, editoras Daniela Jara y Carolina Aguilera, Museo de la Memoria y los Derechos Humanos, Foro Urbano, 2017, pp. 16-33.

Guasch, Anna María. "El giro de la memoria y el giro del archivo en las prácticas artísticas contemporáneas". Revista 180, no. 29, 2012, pp. 2-5.

Guzmán, Nancy. Romo. Confesiones de un torturador. Editorial Planeta, 2000.

---. El Fanta. Historia de una traición. Ceibo, 2016.

Iduarte, María Elena. "La experiencia de los archivos de derechos humanos en Chile". Boletín, vol. 64, no. 3, 2014, pp. 79-96.

---. "Implementación de un Archivo Documental para un Sitio de Memoria y DDHH: el caso de la Corporación Parque por la Paz Villa Grimaldi”. Revista General de Información y Documentación, vol. 25, no. 1, 2015, pp. 9-22. https://doi.org/10.5209/rev_rgid.2015.v25.n1.48981 
Herbst, Jennifer, y Patricia Huenuqueo. "Archivos para el estudio del pasado reciente en Chile”. Historizar el pasado vivo en América Latina, directora Anne Pérotin-Dumon, Versión online, 2007. Consultado en octubre de 2019. https://doi.org/10.31819/9783964562609-009

Jara, Daniela, y Carolina Aguilera. "Pasados inquietos. Dilemas en torno al lugar de los perpetradores en las sociedades postconflicto". Pasados Inquietos, editoras Daniela Jara y Carolina Aguilera, Museo de la Memoria y los Derechos Humanos, Foro Urbano, 2017, pp. 8-15.

Jara, Sergio y Erik López. "Citan a declarar a exmilitares que participaron en la quema de microfilms de la dictadura". Reportajes Bío Bío, 12 de abril de 2018.

Jelin, Elizabeth. La lucha por el pasado. Cómo construimos la memoria social. Siglo XXI Editores, 2018.

Joignant, Alfredo. "La duda perpetua: los límites de las políticas públicas de memoria (sobre la muerte en cámara lenta de Allende, Frei y Neruda)". Ponencia presentada en el Seminario Internacional de Memoria y Derechos Humanos: "Crímenes de lesa humanidad y terrorismo de Estado: ¿existen garantías de no repetición?", Parque por la Paz Villa Grimaldi-GAM, 2017. Kornbluh, Peter. Pinochet: los archivos secretos. Editorial Crítica, 2013.

Kruijt, Dirk y Kees Koonings. "Fuerzas Armadas y política en América Latina: perspectivas futuras". Iberoamericana, vol. 2, no. 8, 2002, pp. 7-22.

Lazzara, Michael. "Tres recorridos de Villa Grimaldi". Monumentos, memoriales y marcas territoriales, compiladoras Elizabeth Jelin y Victoria Langland, Editorial Siglo XXI, 2003, pp. 127-148.

---. Civil Obedience. Complicity and Complacency in Chile since Pinochet. University of Wisconsin Press, 2018.

Leal, Francisco. "La doctrina de seguridad nacional: materialización de la guerra fría en América del Sur". Revista de Estudios Sociales, no. 15, 2003, pp. 74-87.

Lechner, Norbert. Obras Escogidas. Tomo I. Ediciones LOM, 2006.

Lira, Elizabeth. "The Chilean Human Rights Archives and Moral Resistance to Dictatorship". International Journal of Transitional Justice, no. 11, 2017, pp. 189-196. https://doi.org/10.1093/ijtj/ijx015

Mallea, Felipe y Sigal Meirovich. “¿Por qué (no) se puede incluir a Pinochet en una muestra museográfica?” 1988-1968: de la transición al largo '68 en Chile, editores Andrés Estefane, et al., Editorial Ariadna, 2019, pp. 284-286.

Millán, Juanita. "Comisiones de la verdad y posibles aprendizajes para el caso colombiano". Papel Político, vol. 20, no. 2, 2015, pp. 1-35. https://doi.org/10.11144/javeriana.papo20-2.cvpa

O'Donnell, Guillermo. Contrapuntos. Ensayos escogidos sobre autoritarismo y democratización. Paidós, 1997. 
O'Donnell, Guillermo y Philippe Schmitter. Transiciones desde un gobierno autoritario. Prometeo, 2010.

Orizo, Riccardo. Hablando con el diablo. Entrevistas con dictadores. Fondo de Cultura Económica, 2007.

https://doi.org/10.26439/contratexto2016.n026.1719

Ortiz, María. Sin título. Acceso Público a la memoria. El rol de los Archivos testimoniales en la democratización de las sociedades postdictatoriales, editores Raúl Rodríguez et al. Corporación Parque por la Paz Villa Grimaldi, 2009, pp.79-98.

Pavez, Jorge. "Sobre cambio social y archivos". Archivos en Chile: miradas, experiencias y desafíos, Comité Nacional de la Memoria del Mundo, DIBAM, 2014, pp. 9-13.

Pizarro, Rodrigo, y Macarena Miranda. "Por primera vez se conocen los cuadernos del ex agente de la DINA Osvaldo Romo". Chilevisión Noticias, 20 de julio de 2015,

Rebolledo, Javier. La danza de los cuervos: el Mocito y el destino final de los detenidos desaparecidos. Planeta, 2016.

Rebolledo, Daniel y Omar Sagredo. "¿Cómo representar a los represores en un sitio de memoria? El caso del Parque por la Paz Villa Grimaldi”. Ponencia presentada en Ciclo Representaciones de la historia reciente y perpetradores en museos del Estado: Límites, Desafíos y Dilemas, COES, 2018.

Rincón, Tatiana. "La verdad histórica: una verdad que se establece y legitima desde el punto de vista de las víctimas". Revista de Estudios SocioJurídicos, vol. 7, 2005, pp. 331-354.

Rodríguez, Raúl et al. Acceso público a la memoria. El rol de los archivos testimoniales en la democratización de las sociedades postdictatoriales. Ediciones de la Corporación Parque por la Paz Villa Grimaldi, 2009.

Ruiz, María Olga. "Los silencios y las palabras: el testimonio como posibilidad". Revista Atenea, no. 509, 2014, pp. 123-137. https://doi.org/10.4067/s0718-04622014000100007

Sagredo, Omar. "De la memoria de las violaciones a los derechos humanos a la articulación de una plataforma para el estudio del pasado reciente: el Archivo Oral del Parque por la Paz Villa Grimaldi (2006-2018) y las políticas de memoria y patrimonialización". Testimonios, vol. 8, no. 8, 2019.

Salazar, Gabriel. Villa Grimaldi (Cuartel Terranova). Historia, testimonio, reflexión. Ediciones LOM, 2013.

Salvi, Valentina. "Los represores como objeto de estudio". Cuadernos del IDES, vol. 32, 2016, pp. 22-41. 
---. "El universo de los represores: una mirada desde los estudios de la memoria en la Argentina". Pasados Inquietos, editoras Daniela Jara y Carolina Aguilera, Museo de la Memoria y los Derechos Humanos, Foro Urbano, 2017, pp. 34-56.

S/A. "No más archivos secretos. Entrevista a Gloria Elgueta". Revista de Gestión Pública, vol. 3, no. 1, 2014, pp.199-206.

Santos-Herceg, José. "Los centros de detención y/o tortura en Chile. Su desaparición como destino". Revista Izquierdas, vol. 26, pp. 256-275. https://doi.org/10.4067/s0718-50492016000100010

Sepúlveda, Víctor. "Semblanzas del torturador pinochetista". Revisitar la catástrofe. Prisión política en el Chile dictatorial, compiladores Carolina Pizarro y José Santos-Herceg, Editorial Pehuén, pp. 189-204.

Skoknic, Francisca. "Miguel Estay, el Fanta: las razones de un verdugo". CIPER Chile, 02 de noviembre de 2007, https://ciperchile.cl/2007/11/02/fanta/

Stoler, Ann Laura. "Colonial Archives and the Arts of Governance". Archival Science, no. 2, 2002, pp. 87-109.

Strejilevich, Nora. "El testimonio de los sobrevivientes: figuración, creación y resistencia". Revisitar la catástrofe. Prisión política en el Chile dictatorial, compiladores Carolina Pizarro y José Santos-Herceg, Editorial Pehuén, 2016, pp. 17-34.

---. El lugar del testigo. Editorial LOM, 2019.

Valdivia, Verónica. El golpe después del golpe. Leigh vs Pinochet. Chile 19601980. Editorial LOM, 2003.

---. "Construction du pouvoir et régime militaire sous Augusto Pinochet". Vingtième Siècle. Revue d'histoire, no. 105, 2010, pp. 93-107. https://doi. org/10.3917/ving.105.0093

---. "Recobrando la democracia: la militarización del conflicto político en Chile". Las largas sombras de la dictadura: a 30 años del plebiscito, editor Julio Pinto, Editorial LOM, 2019, pp.139-167.

Verdugo, Patricia. De la tortura no se habla. Agüero versus Meneses. Catalonia, 2004. Victoriano, Felipe. "Estado, golpes de Estado y militarización en América Latina: una reflexión histórico política". Argumentos, vol. 23, no. 64, pp. 175-193.

Zeitlyn, David. "Anthropology in and of the Archives: Possible Futures and Contingent Pasts. Archives as Anthropological Surrogates". Annual Review Anthropoly, vol. 41, no. 1, 2012, pp. 461-480. https://doi.org/10.1146/annurev-anthro-092611-145721

Zerán, Faride et al. Encuentros con la memoria. Archivos y debates de memoria $y$ futuro. Ediciones LOM, 2004. 